(2) Open Access Full Text Article

\title{
Patients' experience and perspectives on the rational use of drugs in Turkey: a survey study
}

This article was published in the following Dove Press journal:

Patient Preference and Adherence

8 October 2012

Number of times this article has been viewed

\author{
Nesrin Filiz Basaran' \\ Ahmet Akici \\ 'Kartal Training and Research Hospital, \\ Istanbul, Turkey; ${ }^{2}$ Department of \\ Medical Pharmacology, Marmara \\ University School of Medicine, \\ Istanbul, Turkey
}

Aim: Physicians' inappropriate prescribing habits affect patients' lives both medically and financially. To avoid these unwanted situations, the World Health Organization defined the rational use of drugs (RUD) in 1985. This study aimed to investigate whether patients were as informed about their diagnosis and medication as anticipated and their knowledge about the RUD in general.

Methods: A questionnaire was given to 260 patients being treated at the Kartal Training and Research Hospital between February and March 2012.

Results: Most of the patients declared that they were not informed enough about their diagnosis and not all of the physicians evaluated their therapies. These undesirable conditions were due to high daily examined patient numbers. A total of $68.6 \%$ of patients stated that time allotted per patient was $0-10$ minutes, $33.1 \%$ found the information given sufficient, and $11.3 \%$ were told to repeat back narratives about their treatments. Instructions and warnings given by physicians about prescribed drugs did not fully meet the RUD criteria. The majority of referred patients were willing to be educated about the subject.

Conclusion: These results showed that heavy patient load seriously affects the RUD process. Improvement of the current health system should be given serious consideration. After sufficient arrangements have been made in this field, patients will be able to be informed properly about medicines prescribed by their physicians. Also, public education programs will be helpful to raise awareness of the subject on a larger scale.

Keywords: rational use of drugs, prescribed medicine, patient load, medical information, public education

\section{Introduction}

The World Health Organization (WHO) reported that around the world, 50\% of all medicines are prescribed, dispensed, or sold inappropriately, while $50 \%$ of patients fail to take their medicines adequately. ${ }^{1}$ The irrational use of drugs (IUD) is a global healthcare problem. Polypharmacy, overprescription of injections, choice of more expensive drugs, underuse of available effective medicine, inappropriate self-medication, overuse of antibiotics, failure to prescribe in accordance with clinical guidelines, and insufficient attention to nonpharmacologic options are some of the examples of IUD. Irrational prescribing habits of physicians can lead to wasted resources and can cause medication errors, adverse drug reactions, and loss of patients' confidence in physicians and health-care authorities. ${ }^{1-3}$

The rational use of drugs (RUD), as defined by the WHO, means "Patients receive medications appropriate to their clinical needs, in doses that meet their own
Correspondence: Nesrin Filiz Basaran Kartal Training and Research Hospital, Cevizli Mh., 34865 Kartal, İstanbul, Turkey Tel +9021637l 8769

Email nesfiliz@gmail.com 
individual requirements, for an adequate period of time, and at the lowest cost to them and their community." "There are twelve core components defined by the WHO about promoting more rational use of drugs, including encouraging countries to mandate a multidisciplinary national body to coordinate medicine use policies, preparing an essential medicines list (satisfying the priority health-care needs of the population), establishing clinical guidelines (standard treatment guidelines, prescribing policies), and public education about medicines. $^{5}$

Although there are many reasons to promote RUD, most of the responsibility falls on physicians. However, physicians' efforts towards rational prescribing alone are insufficient; this should be supported by patient implementation. To get a successful RUD process, the relationship between physician and patient has to be as follows. The process of rational prescribing begins with accurate diagnosis, then assessing the prognosis and determining treatment goals (preventive, curative, or symptom-relieving). This process can be summarized as a six-step approach. Physicians should (1) evaluate and clearly define the patient's problem, (2) specify the therapeutic objective, (3) select the appropriate drug therapy, (4) initiate therapy with appropriate details and consider nonpharmacologic therapies, (5) give information, instructions, and warnings, and (6) evaluate therapy regularly (eg, monitor treatment results, consider discontinuation of the drug). ${ }^{6-9}$ Physicians need enough time to achieve these steps at their daily medical practice successfully, which is very difficult these days because of heavy patient loads. It is for nothing if physicians do not allocate adequate time to their patients.

Patients take an important place in rational prescribing decisions. Their beliefs and expectations directly affect the success of the treatment. Physicians should inform patients fully about each prescribed medicine. Patients need to know why they take medicine, how the medicine works, how to take medicine, expected benefits, common and serious side effects, and when to return for a follow-up. Patients who establish clear communication with prescribers have improved compliance, more confidence in prescribers, and greater satisfaction with health-care services. ${ }^{9}$ Patient adherence is a fundamental component of RUD and can be defined as patients following the instructions they are given for the prescribed treatment. ${ }^{10}$

In recent years, there have been intensive studies in Turkey to raise awareness and promote rational prescribing. The Turkish Ministry of Health set up a branch office working on RUD in each province and an RUD team at each hospital working on the subject. In this study, we aimed to investigate knowledge about RUD and information given by physicians about the treatment process among patients who had been referred to the Kartal Training and Research Hospital (KTRH).

\section{Methods}

\section{Study design and sample}

This study was conducted between February and March 2012 at the KTRH, the largest hospital on the Anatolian side of Istanbul, which is located in the Kartal district (population of 501,209 in 2008) and has a 765-bed capacity. A questionnaire comprised of 28 questions was given to patients. After questions relating to some sociodemographic characteristics, the first section of the questionnaire consisted of questions about time spent on the patient.

\section{Data collection}

Face-to-face interviews were conducted with patients ( $n=260)$ who were admitted to KTRH inpatient clinics and had agreed to participate in the study (response rate 98\%). The data-collection period was 30 days, and the survey was taken after the consultation and treatment.

Diagnosis and some demographic information (age, sex), time allocated to the patient (how much time is spent per patient, whether the time is enough for consultation, how many patients can be examined in one day by physician) information given about the patient's medical condition (name, cause, consequences, complications of the disease, nonpharmacologic options, evaluating therapy), information given about prescribed medicines (reason for taking the medicine, name, action, operating instructions, dose, treatment period, drug-food interaction, warning), and patient knowledge about RUD (efficacy, safety, suitability, cost, dosage, period) were questioned and recorded.

\section{Ethical considerations}

The survey was approved by the Turkish Ministry of Health Kartal Training and Research Hospital Scientific Research Evaluation Committee. Informed consent was obtained verbally from the patient or legal guardian (when the patient was not able to give consent).

\section{Statistical analysis}

Data management and computations of descriptive statistics of the survey were performed using SPSS for Windows software (IBM, Armonk, NY). 


\section{Results}

A total of 260 patients participated in the survey, aged $40.0 \pm 18.4$ years, $42.9 \%$ of whom were male. Most of the patients were being seen at this hospital for the first time (68.8\%), others for check-up (15.2\%), had been referred $(8.5 \%)$, or were getting a doctor's prescription $(0.4 \%)$ or a health report $(0.4 \%)$. Patients referred to all clinics were included. They numbered 105 (40.4\%) from internal and 155 (59.6\%) from surgical clinics.

Approximately half of the participants (45.6\%) declared that physicians spent $6-10$ minutes per patient. This was followed by less than 5 minutes (23\%), 11-15 minutes (18.3\%), more than 20 minutes $(9.1 \%)$, and 16-20 minutes (4\%). Over half of the participants $(50.4 \%)$ found the allocated time for consultation enough. Most of the patients (58.4\%) declared that 10-20 minutes was enough for consultation, followed by $5-10$ minutes $(22 \%)$ and more than 20 minutes (19.6\%). When participants were questioned as to the appropriate number of patients examined daily per physician, $46.6 \%$ said 21-30 patients, followed by 1-20 patients (25.7\%), $31-40$ patients $(22.5 \%)$, and more than 40 patients $(5.2 \%)$. Patients were asked whether a physician's ability to make an accurate diagnosis would be affected when the number of patients examined daily rises. Half of them answered "always," 37.3\% "sometimes," and 12.7\% "never." When patients were asked how often they obtained a prescription without a physical examination, 14\% answered "always," $36.6 \%$ "sometimes," and 49.4\% "never."

The next section of the questionnaire raised questions concerning prescribed drugs and written prescriptions. A total of $16 \%$ of patients "always" and $42.6 \%$ "sometimes" demanded prescriptions from physicians at every consultation, $2.8 \%$ thought a doctor who prescribes medicine is a better doctor, $11.8 \%$ stated that there was a positive relation between drug price and treatment efficacy, $67.7 \%$ thought there was not any positive relation, and $20.5 \%$ did not have any opinion. Based on the patients' opinions, the average number of medications prescribed was found to be $3.2 \pm 0.8$. With respect to patients' results, three drugs per written prescription was seen most (44.0\%), followed by four drugs (32.1\%), two drugs (18.3\%), more than four drugs (4.4\%), and one drug (1.2\%). Regarding unintelligible prescriptions, $11.4 \%$ of patients reported that they "always" received them, 26.6\% "sometimes," 31.5\% "rarely," and $29.5 \%$ "never". Patients' answers regarding nonpharmacologic recommendations, demanding drug prescriptions, and giving up ongoing therapy are shown in Table 1 .

Patients were asked whether they were given enough information about their diagnosis and prescribed medicines.
Table I Frequencies of patient's habits regarding nonpharmacologic options, requesting prescriptions, and giving up ongoing therapy

\begin{tabular}{llll}
\hline Questions & Answers & $\mathbf{n}$ & $\%$ \\
\hline Do you take into consideration & Yes & 141 & 56.1 \\
nonpharmacologic recommendations & Sometimes & 84 & 33.5 \\
of your physician about your treatment? & No & 26 & 10.4 \\
& Total & $25 \mathrm{I}$ & 100.0 \\
Do you ask your physician to prescribe & Yes & 17 & 6.6 \\
drugs which have been recommended & Sometimes & 79 & 31.0 \\
by others or previously used? & No & 159 & 62.4 \\
& Total & 255 & 100.0 \\
Do you give up your ongoing therapy & Yes & 21 & 8.3 \\
if you think you have recovered? & Sometimes & 82 & 32.3 \\
& No & 151 & 59.4 \\
& Total & 254 & 100.0 \\
\hline
\end{tabular}

Almost half of the patients reported that they were not informed about the name, cause, consequence, or complications of their diagnosis and treatment (Table 2). The reason for taking the medicine, name, action, dose, operating instructions, treatment period, and warnings were not properly explained (Table 3 ). Besides this, the information given about drug side effects and food-drug interaction was quite narrow. Of the participants, $33.1 \%$ found the information given about drugs by the physician adequate. One of ten physicians $(11.3 \%)$ asked patients to repeat narratives they were told. To the question "Whose assignment is to explain the prescription?", $61 \%$ of the patients said, "both physicians and pharmacists," $30.7 \%$ "only physician," and $8.0 \%$ "only pharmacist."

The last section of the questionnaire was designed to investigate patients' knowledge regarding the RUD (Table 4). Patients' opinions about the RUD were listed as effectiveness, suitability, safety, cost-effectiveness, suitable dosage, and appropriate period. A majority of the patients had not heard about the RUD before (78.9\%). Most of the patients $(85.1 \%)$ reported that they were pleased to be informed about the theme.

Table 2 Distribution of patients' declaration about information given by physicians concerning diagnosis and treatment

\begin{tabular}{lll}
\hline Information given about & $\mathbf{n}$ & $\%$ \\
\hline Diagnose & & \\
$\quad$ Name & 198 & 77.0 \\
Cause & 146 & 56.8 \\
Complications & 140 & 54.5 \\
$\quad$ Consequences & 134 & 52.1 \\
Treatment & & \\
$\quad$ Nonpharmacologic recommendations & 50 & 19.7 \\
Evaluating therapy & 168 & 65.4 \\
\hline
\end{tabular}


Table 3 Distribution of patients declarations about information given by physicians concerning their treatment

\begin{tabular}{lll}
\hline $\begin{array}{l}\text { Information given about } \\
\text { prescribed medicine(s) }\end{array}$ & $\mathbf{n}$ & $\%$ \\
\hline Treatment period & 157 & 61.1 \\
Reason for taking the medicine & 153 & 59.5 \\
Giving instructions & 145 & 56.4 \\
Dose & 135 & 52.7 \\
Name & 129 & 50.2 \\
Action & 116 & 45.1 \\
Warnings & 113 & 44.0 \\
Possible side effects & 92 & 35.8 \\
Drug-food interactions & 82 & 31.9 \\
\hline
\end{tabular}

\section{Discussion}

Patients must be an active participant in their treatments according to RUD principles. ${ }^{4,6}$ In this study, we tried to investigate both directly and indirectly the RUD from the patients' perspective. It is essential to know a patient's knowledge, habits, and attitude toward drug use to be of greater service within the scope of the RUD. Making the patient a part of this process will increase the patient's adherence to the treatment. ${ }^{6-9,11}$ On the other hand it is important to evaluate health services from the patient's point of view. Patients proceeding and adhering to treatment is a vital factor in the RUD process. Making the patient part of the treatment will raise effectiveness, decrease harm, and show respect for the patient's choice.

According to the survey's results, patients declared that physicians did not give enough information to them. This finding shows that physicians did not pay enough attention to explaining the side effects and food-drug interactions as well as other information about drugs. Giving sufficient information about expected side effects can make the patient more aware of issues that in turn can have a positive effect within the scope of both the RUD and pharmacovigilance. ${ }^{12}$ According to RUD criteria, physicians have the responsibility to inform patients about their diseases as well as the intended use of prescribed drugs and the expected outcomes

Table 4 Distribution of patients' perceptions about the rational use of drugs

\begin{tabular}{lll}
\hline Patients' perceptions & $\mathbf{n}$ & $\%$ \\
\hline Prescribing suitable drug to the patient & 198 & 78.0 \\
Prescribing suitable dosage of drug & 183 & 72.0 \\
Prescribing effective drug to the patient & 176 & 69.0 \\
Prescribing safe drug to the patient & 171 & 67.1 \\
Using drug for the appropriate period & 132 & 52.2 \\
Prescribing cost-effective drug to the patient & 92 & 36.2 \\
Patient's idea: prescribing drug specially prepared for patient's genetic \\
feature
\end{tabular}

and potential side effects (the common and the rare but serious ones) of each prescribed medication. ${ }^{6-9}$ Physicians must explain how the medication should (and should not) be administered, including any important relationships to food or medications taken simultaneously by the patient. What is more, the doctor should ask the patient to repeat back pertinent instructions for drugs they are concerned about. At the end of the visit, the prescriber should ensure that the patient completely understands the information given and knows when to return for monitoring. ${ }^{8}$

To achieve all these aforementioned tasks within the scope of the RUD, a physician needs time. Unfortunately, as stated by the patients, most of the physicians do not have enough time to spare for them. The high number of patients examined daily and shortage of time allotted per patient can be listed among important challenges of following the RUD. In this narrow time allotted, it is impossible for physicians to evaluate each patient broadly, make decisions correctly, and inform patients sufficiently. As a consequence, the prescription process is influenced by this intensity. This issue was mentioned by health personnel and managers across different platforms. ${ }^{1}$ We also established that our study patients see things the same way. This heavy patient load directly affects physicians' prescribing patterns. Data obtained from the study showed that patients emphasize that the daily number of patient examinations was too great and the allocated time was insufficient for proper consultation. The last finding can be interpreted as a promising outcome to generalize the RUD.

It is well known that ill-informed use of drugs by patients instigates IUD. Although $2.8 \%$ of participants thought of physicians who prescribe medicine as better doctors, this is inconsistent with the general behavior of patients and our other results. Besides participants' demands for prescriptions at every consultation, poor self-treatment attitudes and giving up their ongoing therapies also worsen the situation. All these unfavorable events are reflected in the literature from different countries. For instance, a study done in Jordan showed that $42.5 \%$ of patients applied for self-treatment. ${ }^{13}$ Another study carried out in Turkey stated that patients' drug use before applying to a health center was detected as $42.9 \%{ }^{14}$ In one study performed in Istanbul, results showed that $60 \%$ of parents had used medication for childhood respiratory tract infection before being seen at a hospital. ${ }^{15}$ Also, in another study, results showed that the reason elderly patients go to health centers in the first place is to get prescriptions. ${ }^{16}$ In the same manner, a study undertaken in Izmir reported that the most common reason for going to a health center was getting a prescription. ${ }^{17}$ 
Another result of the survey pointed out that especially nonpharmacologic recommendations were underestimated by physicians. This can be due to patients' persistence in getting drugs and not considering nonmedication condition as a treatment option. Physicians were forced to prescribe medicine with no purpose or economical consideration. Such results, which were noted in a study done in India, emphasized that many of the antibiotics prescribed by physicians were done so in order to satisfy patients' expectations. ${ }^{18}$ One of the prescribing markers is prescribed drugs per prescription, which must be restricted to patients' need for drugs. Our results also stated that polypharmacy was comparatively frequent. Polypharmacy causes serious health problems, such as if the number of drugs taken rises, this can cause adverse drug reactions, drug-drug and drug-food interactions, and decreased patient adherence. We can say that this was caused primarily by patient's wrong attitudes about drug use. These can be called "demand prescriptions from physician at every consultation" and "ask physician to prescribe drugs recommended by others, taken from a pharmacy or previously used." All of these listed situations are important causes of IUD. ${ }^{5,11}$

The most important outcome of the survey pointed out that generally patients wanted to be informed about their pharmacotherapy. This final result was very pleasing, in that the community seemed interested in the subject and ambitious to be educated. This is encouraging, because there are several studies with an emphasis on patients' education about drugs, which is an important issue regarding the RUD and deserves obligatory refinement. .,2,5,19 $^{1}$ Thus public education programs, and illustrated materials such as flyers and leaflets would be very beneficial for society to become conscious about the subject. Recently, several plans of action have begun to be put into practice to raise the awareness of society about the RUD in Turkey. ${ }^{20}$ The education of society beginning from primary school was proposed, and public training and reimbursement issues must be resolved together in coordination with the $\mathrm{MoH}$ and the Turkish Medical Association. ${ }^{20}$ As stated in this study, the lack of awareness about the RUD pointed out how necessary it is to generate information concerning the RUD. Thus far, the first interventions concerning the RUD were started in Turkey in 1992. Activities have taken place over a broad spectrum in the following years in collaboration with $\mathrm{MoH}$, universities, and professional associations. It is promising that some medical schools in Turkey give RUD courses at the intern year of the medical curriculum, and this is being followed by other medical schools. ${ }^{21,22}$ Although studies about the RUD in Turkey have taken place for 20 years, it can be said that these interventions were insufficient and did not reflect in daily practice and patients' habits.

Although we strove for optimal conditions, this study has some limitations. Patients taking the survey in a hospital atmosphere might have partially affected the patients' ability to give answers freely or in an unbiased manner. In spite of the fact that there was an explanatory statement at the beginning of the survey not to be worried, participants may have been anxious in part during the survey. Besides this, the study was based solely on patients' statements, and we did not apply any other method to measure their RUDrelated opinions.

According to the results of the survey, this study demonstrates that the RUD was not fully achieved, for reasons grounded in high number of patients, lack of knowledge about the subject, and patients' ill-informed attitudes towards medicine use. These results indicate that patients need to be informed and trained in detail about the prescribed medicines, primarily by their physicians but also through public education programs.

\section{Acknowledgments}

The authors would like to thank the KTRH-RUD team for their cooperation and interest. We are grateful to Dr Osman Sumengen and Seher Topalhasan for their collaboration.

\section{Disclosure}

The authors report no conflicts of interest in this work.

\section{References}

1. World Health Organization. Medicines: rational use of medicines. Fact sheet no 338. 2010. Available from: http:/www.who.int/mediacentre/ factsheets/fs338/en/index.html. Accessed September 13, 2012.

2. Management Sciences for Health. Pharmaceutical management. 2011. Available from: http://www.msh.org/expertise/pharmaceutical-management index.cfm. Accessed September 13, 2012.

3. Le Grand A, Hogerzeil HV, Haaijer-Ruskamp FM. Intervention research in rational use of drugs: a review. Health Policy Plan. 1999;14: 89-102.

4. World Health Organization. The Rational Use of Drugs: Report of the Conference of Experts, Nairobi, November 25-29, 1985. Geneva: WHO; 1987.

5. World Health Organization. Promoting rational use of medicines: core components. WHO Policy Perspectives on Medicine. Geneva: WHO; 2002.

6. De Vries TP, Henning RH, Hogerzeil HV, Fresle DA. Guide to Good Prescribing: A Practical Manual. Geneva: WHO; 1994.

7. De Vries TP. Presenting clinical pharmacology and therapeutics: a problem based approach for choosing and prescribing drugs. Br J Clin Pharmacol. 1993;35:581-586.

8. Pollock M, Bazaldua OV, Dobbie AE. Appropriate prescribing of medications: an eight-step approach. Am Fam Physician. 2007;75:231-236.

9. Maxwell S. Rational prescribing: the principles of drug selection. Clin Med. 2009;9:481-485. 
10. Haynes RB, Yao X, Degani A, Kripalani S, Garg A, McDonald HP. Interventions for enhancing medication adherence. Cochrane Database Syst Rev. 2005;4:CD000011.

11. Holloway K, Van Dijk L. The World Medicines Situation 2011: Rational Use of Medicines. Geneva: WHO; 2011.

12. Akici A, Oktay S. Rational pharmacotherapy and pharmacovigilance. Curr Drug Saf. 2007;2:65-69.

13. Yousef AM, Al-Bakri AG, Bustanji Y, Wazaify M. Self-medication patterns in Amman, Jordan. Pharm World Sci. 2008;30:24-30.

14. Uskun E, Uskun SB, Öztürk M, Kişioğlu AN. Drug usage before applying to primary care unit. Sted. 2004;13:451-454.

15. Akici A, Kalaça S, Uğurlu MU, Oktay S. Prescribing habits of general practitioners in the treatment of childhood respiratory-tract infections. Eur J Clin Pharmacol. 2004;60:211-216.

16. Akıcı A, Kalaça S, Uğurlu MÜ, Çalı Ş, Oktay Ş. Evaluation of rational drug use of general practitioners in management of elderly patients. Turk J Geriatr. 2001;4:100-105.
17. Arslan LS, Şemin S. Attitudes and practices of primary healthcare center patients about drug use in Turkey. Patient Educ Couns. 2006;62:250-259.

18. Kotwani A, Wattal C, Katewa S, Joshi PC, Holloway K. Factors influencing primary care physicians to prescribe antibiotics in Delhi India. Fam Pract. 2010;27:684-690.

19. Akici A, Kalaca S, Uğurlu MU, Toklu HZ, Iskender E, Oktay S. Patient knowledge about drugs prescribed at primary healthcare facilities. Pharmacoepidemiol Drug Saf. 2004;13:871-876.

20. Refik Saydam Hifzissihha School Directorate. Workshop on Rational Drug Use. Ankara: Ministry of Health; 2006.

21. Akici A, Gören Z, Aypak C, Terzioglu B, Oktay S. Prescription audit adjunct to rational pharmacotherapy education improves prescribing skills of medical students. Eur J Clin Pharmacol. 2005;61:643-650.

22. Akici A, Kalaça S, Gören MZ, et al. Comparison of rational pharmacotherapy decision-making competence of general practitioners with intern doctors. Eur J Clin Pharmacol. 2004;60:75-82.

\section{Publish your work in this journal}

Patient Preference and Adherence is an international, peer-reviewed, open access journal focusing on the growing importance of patient preference and adherence throughout the therapeutic continuum. Patient satisfaction, acceptability, quality of life, compliance, persistence and their role in developing new therapeutic modalities and compounds to optimize clinical outcomes for existing disease states are major areas of interest. This journal has been accepted for indexing on PubMed Central. The manuscript management system is completely online and includes a very quick and fair peer-review system. Visit http://www.dovepress.com/ testimonials.php to read real quotes from published authors. 